\title{
Inventarisasi Jenis Pohon di Kawasan Pusat Pembinaan, Pendidikan, dan Pelatihan (Pusbindiklat) Peneliti - LIPI untuk Menunjang Faktor Keselamatan
}

\author{
I PUTU GEDE P. DAMAYANTO1* ${ }^{*}$ RADEN PRAMESA NARAKUSUMO ${ }^{1}$, \\ ENDANG KINTAMANI ${ }^{1}$, ADE LIA PUTRII ${ }^{1}$, A'LIYATUR ROSYIDAH ${ }^{1}$, SENLIE \\ OCTAVIANA², BUGI RATNO BUDIARTO2 ${ }^{2}$ FIQOLBI NURO POHAN², \\ RAHAYU FITRIANI WANGSA PUTRIE ${ }^{2}$, ARIEF NOOR RACHMADIYANTO3
}

1. Pusat Penelitian Biologi - LIPI,

Jl. Jakarta-Bogor Km 46 Cibinong, Jawa Barat, 16911, Indonesia

2. Pusat Penelitian Bioteknologi - LIPI,

Jl. Jakarta-Bogor Km 46 Cibinong, Jawa Barat, 16911, Indonesia

3. Pusat Konservasi Tumbuhan, Kebun Raya Bogor - LIPI,

Jl. Ir. H. Juanda No. 13 Bogor, Jawa Barat, 16003, Indonesia

*E-mail: parlida.damayanto.tab@gmail.com

\begin{abstract}
Trees Inventory in National Training and Education Center for Researchers Development - Indonesian Institute of Sciences for Safety Support
\end{abstract}

The area within Pusbindiklat Peneliti-LIPI (The National Training and Education Center for Researchers Development-Indonesian Institute of Sciences) has been planted with many trees as an effort for reforestration and increasing aesthetic value. Unfortunately, the management of Pusbindiklat Peneliti-LIPI paid less attention to the trees potency and its characteristic as well as inventorizing all trees. This study aim to inventorize tree species based on their morphological characteristic in order to know the potency concerned with safety. Research was conducted through inventorizing and scoring the suitability factors of all trees, determining the tree plantation points, which is converted to the map of Pusbindiklat Peneliti-LIPI. In addition, direct interviews were also conducted to the civitas of Pusbindiklat Peneliti-LIPI. Trees that have been found in the area of Pusbindiklat Peneliti-LIPI consist of 20 family, 42 species, and 217 individuals. From the inventory of the trees, there were 11 species which were unsuitable with the criteria of urban forest vegetation parameter. Moreover, based on the map of trees species at Pusbindiklat Peneliti-LIPI area, there are 85 individual from 20 species of trees that are not suitable to be planted in Pusbindiklat Peneliti, since they were planted near the parapet wall and buildings of Pusbindiklat Peneliti-LIPI.

Keywords: trees, safety, Pusbindiklat Peneliti-LIPI 


\section{Pendahuluan}

Pusat Pembinaan, Pendidikan, dan Pelatihan Peneliti Lembaga IImu Pengetahuan Indonesia (Pusbindiklat Peneliti-LIPI) yang berlokasi di kawasan Cibinong Science Center (CSC) LIPI merupakan hasil perkembangan organisasi, pembaharuan struktur, serta penyempurnaan tugas dan fungsi LIPI sebagai instansi pembina jabatan fungsional peneliti (Keputusan Kepala LIPI Nomor 1151/M/2001 tentang Organisasi dan Tata Kerja LIPI, jo Nomor 3212/M/2004 tanggal 28 Oktober 2004, tentang Perubahan atas Organisasi dan Tata Kerja LIPI yang direvisi menjadi Peraturan Kepala LIPI Nomor 1 Tahun 2014 tentang Organisasi dan Tata Kerja LIPI). Pusbindiklat Peneliti-LIPI bertugas untuk melaksanakan pembinaan administrasi peneliti, dan pendidikan dan pelatihan jabatan fungsional peneliti dan non-peneliti serta teknis dan kedinasan. Perubahan tersebut membuat peran Pusbindiklat Peneliti-LIPI menjadi lebih luas dan terarah dalam mengemban fungsi LIPI sebagai instansi pembina jabatan fungsional peneliti, termasuk melakukan pembinaan dan menyelenggarakan pendidikan dan pelatihan bagi peneliti (Pusbindiklat-Peneliti-LIPI 2016).

Pengelola Pusbindiklat Peneliti-LIPI telah menata ruang terbuka hijau (RTH) dengan menanam berbagai jenis pohon di kawasan Pusbindiklat Peneliti-LIPI untuk mengurangi tingkat polusi udara dan menambah nilai estetika. Ruang terbuka hijau merupakan area yang memanjang/jalur dan mengelompok yang penggunaannya lebih bersifat terbuka, tempat tumbuh tanaman baik yang tumbuh secara alamiah maupun yang sengaja ditanam (DJPR-DPU 2008; Departemen-PU 2012). Selain berfungsi untuk mengurangi polusi udara, RTH juga berfungsi dalam meningkatkan kualitas air tanah, mencegah banjir, dan sebagai pengatur iklim mikro (DJPR-DPU 2008). Akan tetapi pemilihan jenis pohon yang akan ditanam perlu diperhatikan agar pohon dapat berfungsi dengan maksimal.

Keberadaaan pohon akan berfungsi secara maksimal jika pemilihan suatu jenis pohon sesuai dengan tempat dan peruntukkan pada tiap kawasan. Secara umum pohon berperan untuk menyerap $\mathrm{CO}_{2}$ dan mengeluarkan $\mathrm{O}_{2}$. Akan tetapi, secara individu setiap pohon mempunyai karakteristik dan fungsi yang berbeda seperti menyerap polutan, meredam kebisingan, menyerap aroma tidak sedap, dan penggunaan dalam hal estetika. Berdasarkan Departemen-PU (2012), posisi peletakkan pohon harus diperhatikan. Hal tersebut dilakukan untuk menunjang faktor keselamatan di sekitar pohon yang ditanam, seperti pertimbangan jarak tanam dengan bangunan di sekitarnya. Lebih jauh dijelaskan pula bahwa jenis pohon yang ditanam di tepi jalan tidak boleh melebihi tinggi kabel pada tiang listrik, tanpa harus memotong cabang terus menerus. Selain itu, tanaman tidak boleh merusak struktur utuh bawah tanah. Menurut Departemen-PU (2012), pohon yang ditanam juga harus diatur agar bayangan pohon tidak mencukupi pancaran cahaya lampu dan jarak atur tanaman empat meter dari bangunan.

Pengelola Pusbindiklat Peneliti-LIPI telah memanfaatkan RTH untuk mengurangi polusi udara dan menambah estetika lokasi, namun pengelola Pusbindiklat Peneliti-LIPI belum melakukan inventarisasi pohon yang terdapat di sekitar Pusbindiklat Peneliti-LIPI. Hal tersebut terjadi karena Pusbindiklat Peneliti-LIPI belum memasukkan jenis-jenis pohon di dalam masterplan-nya. Oleh karena itu, perlu dilakukan inventarisasi jumlah dan jenis 
pohon yang berada di kawasan Pusbindiklat Peneliti-LIPI sebagai bahan dasar mengetahui potensi pepohonan terkait faktor keselamatan dan kesesuaian dengan vegetasi hutan kota berdasarkan karakter pohon.

\section{Metode}

Penelitian ini dilakukan di kampus Pusat Pembinaan Pendidikan dan Pelatihan (Pusbindiklat) Peneliti-LIPI, Cibinong Science Center (CSC), Jl. Jakarta-Bogor Km 46 Cibinong, Kabupaten Bogor, Jawa Barat, menggunakan metode observasi dan wawancara yang terdiri dari pengumpulan data sekunder dan primer. Data sekunder berupa peta lokasi Pusbindiklat Peneliti-LIPI yang digunakan sebagai pedoman untuk melakukan konversi penentuan titik lokasi penanaman pohon. Data primer berupa inventarisasi jenis pohon, penentuan posisi penanaman pohon, dan data hasil wawancara langsung dengan para sivitas di lingkungan Pusbindiklat Peneliti-LIPI.

Inventarisasi jenis pohon dilakukan dengan pengamatan langsung meliputi pencatatan suku, nama latin, nama lokal, dan jumlah individu. Jenis pohon diidentifikasi menggunakan pustaka acuan Flora of Java Volume 1 (Backer dan Brink 1963), Volume 2 (Backer dan Brink 1965), Volume 3 (Backer dan Brink 1968), dan Flora Malesiana Seri I Volume 12 (Mabberley, dkk. 1995). Dilakukan penilaian karakteristik kesesuaian dari masing-masing jenis pohon. Karakter pohon yang diamati adalah tinggi, kecepatan tumbuh, kekokohan, kedalaman akar, kerapatan tajuk, keindahan tajuk, mudah tidaknya daun berguguran, ketebalan daun, ukuran daun, dan berbulu tidaknya daun (Samsoedin 2009 dalam Mulyana 2013). Selain itu, juga dilakukan pengukuran posisi pohon terhadap bangunan (tembok dan gedung) (DJPR-DPU 2008). Setiap lokasi penanaman pohon dilakukan pencatatan titik koordinat, kemudian dilakukan konversi titik koordinat tersebut dengan peta kawasan Pusbindiklat Peneliti-LIPI. Wawancara secara langsung (metode purposive) dilakukan untuk memperoleh informasi potensi pohon terkait faktor keselamatan di kawasan Pusbindiklat Peneliti-LIPI. Koresponden wawancara terdiri dari 13 sivitas Pusbindiklat Peneliti-LIPI (pegawai adminstrasi, widyaiswara, satpam, dan petugas kebersihan).

Data primer dianalisis untuk mengkaji kriteria kesesuaian penanaman jenis pohon yang memiliki diameter lebih dari $10 \mathrm{~cm}$ pada setiap titik pengamatan di kawasan Pusbindiklat Peneliti-LIPI dengan mengacu pada metode analisis rencana penelitian intregatif (Samsoedin 2009 dalam Mulyana 2013). Selain parameter pohon berdasarkan karakteristik yang diamati, ditambah dengan persyaratan penanaman pohon untuk kawasan perkantoran lebih dari empat meter dari bangunan (DJPR-DPU 2008). Disusun penilaian "kesesuaian jenis pohon" dengan rumus kriteria berdasarkan Mulyana (2013) berikut.

$$
K s=(X n+Y n)-Y n
$$

Keterangan:

Ks $=$ Kriteria kesesuaian suatu jenis pohon.

$\mathrm{Xn} \quad=$ Jumlah karakteristik suatu jenis pohon yang tepat untuk setiap tipe kawasan hutan kota dan diberi angka 1 bila karakteristik sesuai.

$\mathrm{Yn}=$ Jumlah karakteristik suatu jenis pohon yang kurang tepat untuk setiap tipe kawasan hutan kota dan diberi angka nol jika karaktersitik kurang sesuai. 
Kriteria kesesuaian jenis pohon dinyatakan dalam bentuk skor dengan interpretasi yang dapat dilihat pada Tabel 1 . Selanjutnya hasil analisis tersebut dikuatkan dengan hasil wawancara dengan sivitas Pusbindiklat Peneliti-LIPI.

Tabel 1. Kriteria Kesesuaian Jenis Pohon

\begin{tabular}{ll}
\hline Skor & Kriteria Keseuaian \\
\hline Ks $\geq 8$ & Sangat sesuai \\
$5 \geq$ Ks $\leq 7$ & Sesuai \\
Ks $\leq 4$ & Kurang sesuai \\
\hline
\end{tabular}

Sumber: Mulyana 2013

\section{Hasil dan Pembahasan}

\subsection{Hasil Penelitian}

\subsubsection{Keanekaragaman Jenis Pohon di Kawasan Pusbindiklat Peneliti-LIPI}

Berdasarkan hasil observasi dan hasil identifikasi jenis-jenis pohon di kawasan Pusbindiklat Peneliti-LIPI, ditemukan sebanyak 20 suku, 42 jenis, dan 217 individu. Tiga suku yang mendominasi adalah Fabaceae, Myrtaceae, dan Sapindaceae. Tiga jenis pohon yang mendominasi adalah Mangifera sp., Magnolia sp., dan Nephelium sp. (Tabel 2).

\subsubsection{Matrik Kesesuaian Jenis Pohon di Kawasan Pusbindiklat Peneliti-LIPI}

Berdasarkan hasil analisis skor matriks kesesuaian jenis pohon diperoleh rentang skor 2 sampai dengan 7 (Tabel 2). Jenis-jenis pohon yang memiliki rentang skor 2 sampai dengan 4 mengindikasikan bahwa pohon kurang sesuai dengan karakteristik vegetasi hutan kota. Terdapat sebelas jenis pohon yang kurang sesuai, yaitu Annona sp., Agathis dammara, Cupressus sempervirens, Elaeocarpus grandiflorus, Magnolia sp., Dysoxylum sp., Swietenia macrophylla, Muntingia calabura, Mussaenda pubescens, Pometia pinnata, dan Manilkara kauki.

\subsubsection{Pemetaan Jenis Pohon di Kawasan Pusbindiklat Peneliti-LIPI}

Berdasarkan hasil pemetaan jenis pohon di kawasan Pusbindiklat Peneliti-LIPI terdapat 20 jenis pohon yang ditanam dekat (kurang dari empat meter) dengan tembok batas dan bangunan Pusbindiklat Peneliti-LIPI (Gambar 1, lihat zona bebas pohon). Jenis pohon yang tumbuh dekat dengan tembok batas adalah Agathis damara, Azadirachta indica, Ceiba petandra, Manilcara sp., Mangifera sp., Magnolia sp., Nephelium sp., dan Syzygium aqueum. Jenis pohon yang tumbuh dekat bangunan adalah Artocarpus heterophyllus, Cupressus sempervirens, Elaeocarpus grandiflorus, Manilkara zapota, Manilkara sp., Magnolia champaca, Mangifera indica, Mangifera sp., Mussaenda pebescens, Nephelium sp., Pometia pinnata, Polyalthia longifolia, Syzygium sp., S. aqueum, S. malaccense, dan Psidium sp.

\subsubsection{Hasil Wawancara dengan Sivitas Pusbindiklat Peneliti-LIPI}

Berdasarkan hasil wawancara diperoleh informasi bahwa sudah pernah ada riwayat kejadian pohon tumbang. Pohon yang tumbang di antaranya adalah albizia, dadap merah, palem botol, nangka, mangga, dan rambutan. Pohon-pohon tersebut tumbang karena cuaca buruk (hujan, angin, dan badai) dan keroposnya batang pohon. Kejadian riwayat pohon tumbang ini terkait dengan strategi penanaman pohon di Pusbindiklat Peneliti-LIPI yang dinilai koresponden masih belum tepat. Akan tetapi, dari segi keamanan dan kenyamanan sebesar 62\% koresponden menyatakan sudah aman dan nyaman. Sedangkan 38\% menyatakan belum aman dikarenakan masih terdapat adanya nyamuk dan beberapa hewan lain seperti ular yang menganggu kenyamanan sivitas Pusbindiklat Peneliti-LIPI. 


\subsection{Pembahasan}

\subsubsection{Keanekaragaman Jenis Pohon di Kawasan Pusbindiklat Peneliti-LIPI} Jenis pohon yang berada di kawasan Pusbindiklat Penelitian-LIPI bervariasi dan secara umum didominasi oleh jenis buah-buahan. Pohon jenis mangga (Mangifera sp.) paling banyak ditemukan berdasarkan hasil inventarisasi di Pusbindiklat Peneliti-LIPI (Tabel 2).

Tabel 2. Keragaman dan Skor Matriks Kesesuaian Jenis Pohon di Kawasan Pusbindiklat Peneliti-LIPI

\begin{tabular}{|c|c|c|c|c|c|c|}
\hline . & Suku & Nama Latin & Nama Lokal & Jumlah & Skor & Kriteria \\
\hline 1 & Anacardiaceae & Mangifera indica L. & Mangga & 6 & 5 & Sesuai \\
\hline 2 & Anacardiaceae & Mangifera sp. & Mangga & 45 & 5 & Sesuai \\
\hline 3 & Annonaceae & Annona sp. & Sirsak & 2 & 3 & Kurang sesuai \\
\hline 4 & Annonaceae & Polyalthia longifolia (Sonn.) Thwaites & Glodokan & 9 & 5 & Sesuai \\
\hline 5 & Araucariaceae & Agathis dammara (Lamb.) Rich. \& A.Rich. & Kidamar & 9 & 4 & Kurang sesuai \\
\hline 6 & Bignoniaceae & Jacaranda sp. & Jacaranda & 2 & 5 & Sesuai \\
\hline 7 & Burseracae & Canarium sp. & Kenari & 1 & 5 & Sesuai \\
\hline 8 & Cupressaceae & Cupressus sempervirens L. & Cemara pensil & 7 & 3 & Kurang sesuai \\
\hline 9 & Elaeocarpaceae & Elaeocarpus grandiflorus Sm. & Anyang-anyang & 8 & 4 & Kurang sesuai \\
\hline 10 & Fabaceae & Albizia falcataria (L.) Fosberg & Sengon & 3 & 7 & Sesuai \\
\hline 11 & Fabaceae & Bauhinia purpurea L. & Bunga kupu-kupu & 2 & 5 & Sesuai \\
\hline 12 & Fabaceae & Erythrina crista-galli L. & Dadap merah & 4 & 5 & Sesuai \\
\hline 13 & Fabaceae & Leucaena leucocephala (Lam.) de Wit & Lamtoro & 1 & 6 & Sesuai \\
\hline 14 & Lamiaceae & Tectona grandis L.f. & Jati & 9 & 5 & Sesuai \\
\hline 15 & Lauraceae & Cinnamomum verum J. Presl. & Kayu manis & 2 & 6 & Sesuai \\
\hline 16 & Lauraceae & Persea americana Mill. & Alpukat & 1 & 5 & Sesuai \\
\hline 17 & Lecythidaceae & Barringtonia asiatica (L.) Kurz & Butun & 1 & 7 & Sesuai \\
\hline 18 & Magnoliaceae & Magnolia champaca (L.) Baill. ex Pierre & Cempaka kuning & 3 & 6 & Sesuai \\
\hline 19 & Magnoliaceae & Magnolia sp. & Cempaka & 17 & 2 & Kurang sesuai \\
\hline 20 & Malvaceae & Ceiba pentandra (L.) Gaertn. & Randu & 2 & 7 & Sesuai \\
\hline 21 & Meliaceae & Azadirachta indica A.Juss. & Nimba & 1 & 5 & Sesuai \\
\hline 22 & Meliaceae & Dysoxylum sp. & Majegau & 1 & 4 & Kurang sesuai \\
\hline 23 & Meliaceae & Swietenia macrophylla King & Mahoni & 1 & 4 & Kurang sesuai \\
\hline 24 & Moraceae & $\begin{array}{l}\text { Artocarpus altilis (Parkinson ex. F.A.Zorn) } \\
\text { Fosberg }\end{array}$ & Sukun & 4 & 6 & Sesuai \\
\hline 25 & Moraceae & Artocarpus heterophyllus Lam. & Nangka & 1 & 6 & Sesuai \\
\hline 26 & Moraceae & Artocarpus sp. & Cempedak/Nangka & 2 & 7 & Sesuai \\
\hline 27 & Muntingiaceae & Muntingia calabura $\mathrm{L}$. & Kersen & 1 & 4 & Kurang sesuai \\
\hline 28 & Myrtaceae & Callistemon viminalis (Sol. ex Gaertn.) G.Don & Sikat Botol & 3 & 5 & Sesuai \\
\hline 29 & Myrtaceae & Psidium guajava $\mathrm{L}$. & Jambu biji & 4 & 5 & Sesuai \\
\hline 30 & Myrtaceae & Psidium sp. & Jambu biji & 2 & 5 & Sesuai \\
\hline 31 & Myrtaceae & Syzygium aqueum (Burm. f.) Alston & Jambu air & 4 & 5 & Sesuai \\
\hline 32 & Myrtaceae & Syzygium malaccense (L.) Merr. \& L.M.Perry & Jambu bol & 3 & 5 & Sesuai \\
\hline 33 & Myrtaceae & Syzygium sp. & Pucuk merah & 4 & 5 & Sesuai \\
\hline 34 & Oxalidaceae & Averrhoa carambola L. & Belimbing & 2 & 6 & Sesuai \\
\hline 35 & Rubiaceae & Mussaenda pubescens Dryand. & Nusa indah & 4 & 4 & Kurang sesuai \\
\hline 36 & Sapindaceae & Dimocarpus longan Lour. & Kelengkeng & 1 & 6 & Sesuai \\
\hline 37 & Sapindaceae & Nephelium lappaceum L. & Rambutan & 2 & 6 & Sesuai \\
\hline
\end{tabular}




\begin{tabular}{|c|c|c|c|c|c|c|}
\hline 38 & Sapindaceae & Nephelium sp. & Rambutan & 24 & 6 & Sesuai \\
\hline 39 & Sapindaceae & Pometia pinnata J.R. Forst. \& G. Forst. & Matoa & 3 & 3 & Kurang sesuai \\
\hline 40 & Sapotaceae & Manilkara kauki (L). Dubart & Sawo kecik & 1 & 4 & Kurang sesuai \\
\hline 41 & Sapotaceae & Manilkara zapota (L). P. Royen & Sawo manila & 1 & 7 & Sesuai \\
\hline 42 & Sapotaceae & Manilkara sp. & Sawo & 14 & 6 & Sesuai \\
\hline \multicolumn{4}{|c|}{ Total Individu } & \multicolumn{3}{|l|}{217} \\
\hline
\end{tabular}

Variasi jenis-jenis pohon yang terdapat di kawasan Pusbindiklat Peneliti-LIPI dapat memengaruhi iklim mikro di kawasan ini. Menurut Nowak dan Dwyer (2007) pohon-pohon hutan kota dapat memengaruhi atmosfer di lingkungan perkotaan meliputi efeknya terhadap temperatur dan iklim mikro, pembersihan polutan udara, emisi senyawa organik mudah menguap yang berkontribusi pada pembentukan ozon, serta konservasi energi yang disebabkan oleh pengurangan pemanasan dan pendinginan bangunan. Selain itu, variasi pohon tersebut juga menambah nilai estetika kawasan Pusbindiklat Peneliti-LIPI. DJPR-DPU (2008) menyatakan bahwa pohon berdasarkan nilai estetikanya memiliki fungsi meningkatkan kenyamanan, memperindah lingkungan kota, baik dari skala mikro (halaman rumah, lingkungan permukiman, maupun makro (lansekap kota secara keseluruhan), menstimulasi kreativitas dan produktivitas warga, pembentuk faktor keindahan arsitektural, dan menciptakan suasana serasi dan seimbang antara area terbangun dan tidak terbangun.

\subsubsection{Kesesuaian Jenis Pohon yang Mendukung Faktor Keselamatan di Kawasan Pusbindiklat Peneliti-LIPI \\ Berdasarkan matrik kesesuaian jenis pohon di kawasan Pusbindiklat Peneliti-LIPI} (Tabel 2), Annona sp. kurang sesuai kriteria karena memiliki perakaran yang tidak dalam, tajuk tidak indah, daun mudah rontok, dan daun tidak tebal. Agathis dammara kurang sesuai dengan kriteria karena memiliki perakaran yang tidak dalam, tajuk tidak rapat, tajuk tidak indah, dan daun mudah rontok. Cupressus sempervirens kurang sesuai dengan kriteria karena memiliki daun mudah rontok dan tidak tebal. Elaeocarpus grandiflorus kurang sesuai dengan kriteria karena memiliki perakaran kurang dalam dan tajuk tidak indah. Magnolia sp. kurang sesuai dengan kriteria karena memiliki perakaran yang tidak dalam dan daunnya tidak tebal. Dysoxylum sp. kurang sesuai dengan kriteria karena memiliki tajuk tidak indah. Swietenia macrophylla kurang sesuai dengan kriteria karena tajuk yang tidak indah dan daun tidak tebal. Muntingia calabura kurang sesuai dengan krteria karena memiliki perakaran yang tidak dalam, tajuk tidak rapat, tajuk tidak indah, serta memiliki daun yang mudah rontok, tidak tebal, dan berbulu. Mussaenda pubescens kurang sesuai kriteria karena memiliki daun mudah rontok, tidak tebal, dan berbulu. Pometia pinnata kurang sesuai dengan kriteria karena memiliki perakaran yang tidak tidak dalam, daun mudah rontok dan tidak tebal. Manilkara kauki kurang sesuai dengan kriteria karena memiliki daun yang mudah rontok dan kurang tebal. 


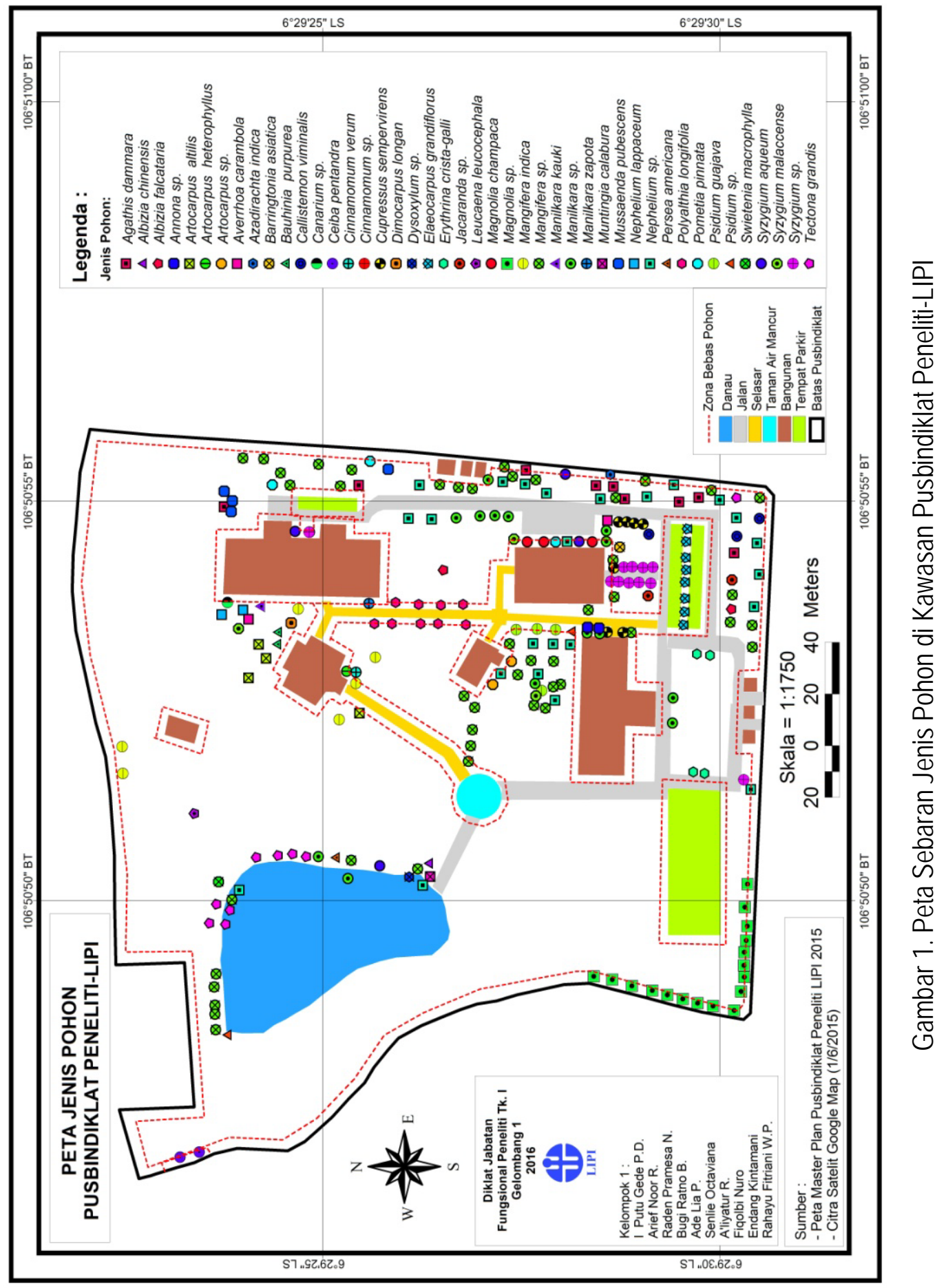


DJPR-DPU (2008) menyatakan kriteria pemilihan vegetasi untuk taman di antaranya dahan tidak mudah patah, perakaran tidak mengganggu pondasi, tajuk cukup rindang dan kompak, perawakan dan bentuk tajuk cukup indah, kecepatan tumbuh sedang, jenis tanaman tahunan atau musiman, jarak tanam setengah rapat sehingga menghasilkan keteduhan yang optimal, tahan terhadap hama penyakit tanaman, dan mampu menyerap cemaran udara.

Pohon yang daunnya mudah luruh dan sulit terurai kurang sesuai dengan kriteria karena dapat menyebabkan tumpukan serasah yang tebal yang berpotensi menyebabkan cidera akibat tergelincir (Mulyana 2013). Pohon yang memiliki perakaran yang tidak dalam berpotensi tumbang umumnya dari kelompok pohon peneduh dan buah (Nazarudin 1996; Bezemer, dkk. 2003). Hal ini didukung dengan hasil wawancara bahwa karakteristik dari pohon-pohon yang pernah tumbang di kawasasn Pusbindiklat Peneliti-LIPI termasuk dalam kategori pohon peneduh dan pohon buah. Sedangkan jenis pohon lainnya sudah sesuai dengan kriteria karena memenuhi kriteria sebagai pohon peneduh dan lokasinya sudah sesuai berdasarkan jarak dari bangunan.

\subsubsection{Jarak tanam Pohon dan Faktor Keselamatan}

Kesesuaian penanaman jenis pohon juga harus mempertimbangkan lokasi tanam. Di dalam Undang-Undang No. 26 Tahun 2007 tentang Penataan Ruang, perencanaan tata ruang wilayah kota harus memuat rencana penyediaan dan pemanfaatan ruang terbuka hijau yang luas minimalnya sebesar 30\% dari luas wilayah kota (DJPR-DPU 2008). Lebih jauh dijelaskan bahwa pohon peneduh yang ditanam di area selasar dan dekat bangunan berpotensi merusak pondasi dan struktur bangunan. Menurut Departemen-PU (2012), pohon sebaiknya ditanam lebih dari empat meter dari bangunan. Jika pohon tesebut ditanam di area ruang terbuka hijau (RTH) maka jenis pohon tersebut tidak berpotensi mengancam faktor keselamatan. Hal ini dapat menjadi acuan untuk luas taman di Pusbindiklat Peneliti-LIPI. Oleh karena itu, rekomendasi yang dapat kami berikan adalah tidak menanam pohon kurang dari empat meter dari batas pondasi bangunan. Selain itu, disarankan menaman jenis pohon pemecah angin, di antaranya cemara (Cassuarina equisetifolia), mahoni (Swietania mahagoni), tanjung (Mimusops elengi), kiara payung (Filicium decipiens) dan kembang sepatu (Hibiscus rosasinensis) (DJPR-DPU 2008).

Melalui hasil penelitian ini dapat menjadi bahan pertimbangan dalam pengambilan kebijakan pengelolaan pohon-pohon di Pusbindiklat Peneliti-LIPI, di mana pohon yang kurang sesuai dan lokasi penanamannya dekat dengan bangunan dapat direlokasi ke area yang jauh dari aktivitas sivitas Pusbindiklat Peneliti-LIPI. Lebih lanjut jenis-jenis pohon yang sesuai untuk ditanam di Pusbindiklat Peneliti-LIPI dengan skor tertinggi (skor 7) menurut hasil analisis penelitian ini adalah Albizia falcataria, Barringtonia asiatica, Ceiba pentandra, Artocarpus sp., dan Manilkara zapota.

\section{Simpulan}

Jenis-jenis pohon yang ditemukan di kawasan Pusbindiklat Peneliti-LIPI sebanyak 20 suku, 42 jenis, dan 217 individu. Terdapat sebelas jenis pohon yang kurang sesuai dengan 
kriteria parameter kesesuaian jenis pohon sebagai vegetasi hutan kota sehingga sebaiknya tidak digunakan sebagai tanaman vegetasi di Pusbindiklat Peneliti-LIPI. Hasil pemetaan jenis pohon di kawasan Pusbindiklat Peneliti-LIPI ditemukan 20 jenis pohon yang ditanam terlalu dekat dengan tembok batas dan bangunan Pusbindiklat Peneliti-LIPI.

\section{Ucapan Terima Kasih}

Tim penulis mengucakan terima kasih kepada Dr. Joko Ridho Witono, M.Si. yang telah memberikan masukan dalam tulisan ini. Terima kasih juga diucapkan kepada sivitas Pusbindiklat Peneliti-LIPI yang telah bersedia menjadi narasumber dalam penelitian ini.

\section{Daftar Pustaka}

Backer, C. A. \& V. D. Brink. 1963. Flora of Java Volume I. Rijks Herbarium, Leiden.

Backer, C. A. \& V. D. Brink. 1965. Flora of Java Volume II. Rijks Herbarium, Leiden.

Backer, C. A. \& V. D. Brink. 1968. Flora of Java Volume III. Rijks Herbarium, Leiden.

Bezemer, T. M., R. Wagenaar, N. M. V. Dam \& F. L. Wackers. 2003. Interactions Between Above- and Belowground Insect Herbivores as Mediated by the Plant Defense System. Oikos, 101(3):555-562.

Departemen-PU. 2012. Pedoman Penanaman Pohon pada Sistem Jaringan. Menteri Pekerjaan Umum Republik Indonesia, Jakarta.

DJPR-DPU. 2008. Pedoman Penyediaan dan Pemanfaatan Ruang Terbuka Hijau di Kawasan Perkotaan. Direktorat Jenderal Penataan Ruang, Departemen PU, Kementrian Pekerjaan Umum, Jakarta.

Mabberley, D. J., C. M. Pannell \& A. M. Sing. 1995. Spermatophyta (Flowering Plants: Meliaceae). Flora Malesiana, 12(1):1-388.

Mulyana, S. 2013. Hutan Kota di Bandung, Jawa Barat (Study of Tree Species Potential for Urban Forest in Bandung City, West Java). Jurnal Analisis Kebijakan Kehutanan, 10(1):58-71.

Nazarudin. 1996. Penghijauan Kota. Penebar Swadaya, Jakarta.

Nowak, D. J. \& J. F. Dwyer. 2007. Understanding the Benefits and Costs of Urban Forest Ecosystems (Urban and Community Forestry in the Northeast). Springer, New York.

Pusbindiklat-Peneliti-LIPI. 2016. Sejarah Pusat Pembinaan, Pendidikan dan Pelatihan Peneliti LIPI, Indonesia. Available online at: http://pusbindiklat.lipi.go.id/web/organisasi/sejarah (accessed 3 February 2017). 